\title{
Face-to-Face Still-Face: Comparison between Interactive Behaviors of Full-Term and Preterm Infants
}

\author{
Taís Chiodelli ${ }^{1}$ \\ Olga Maria Piazentin Rolim Rodrigues ${ }^{1}$ \\ Veronica Aparecida Pereira ${ }^{2}$ (D) \\ Pedro Lopes dos Santos $^{3}$ \\ Marina Fuertes ${ }^{4}$ (iD
}

\begin{abstract}
Some studies indicate differences in self-regulatory behaviors of infants, depending on their gestational age. This paper aimed to compare interactive behaviors of full-term and preterm infants in the Face-to-Face Still-Face (FFSF) paradigm. Thirty prematurely born infants and thirty full-term infants were observed in the FFSF's experimental procedure, which consists in exposing the infant to two episodes of interaction with the mother plus another episode in which the interaction gets interrupted. The Coding System and Analysis of Infant Behaviors Expressed in Still-Face adapted was used to analyze the infants' interactive behaviors. Significant differences were observed in self-comfort behaviors. All the infants showed the still-face and the recovery effect, and full-term infants showed a carryover effect. Results contribute to planning interventions that will help mothers promote more positive dyadic interactions.
\end{abstract}

Keywords: premature birth, mother-child relations, emotional regulation

\section{Face-to-Face Still-Face: Comparação entre Comportamentos Interativos de Bebês Nascidos a Termo e Prematuros}

\begin{abstract}
Resumo: Estudos têm apresentado diferenças nos comportamentos de autorregulação de bebês quando considerada a idade gestacional. Este estudo teve por objetivo comparar comportamentos interativos de bebês nascidos a termo e prematuros segundo paradigma experimental do Face-to-Face Still-Face (FFSF). Trinta bebês nascidos prematuros e trinta a termo foram observados no procedimento experimental do FFSF que consiste na exposição do bebê a dois episódios de interação com a mãe e a um episódio em que se interrompe a interação. Utilizou-se uma adaptação do Sistema de Codificação e de Análise dos Comportamentos Infantis Expressos no Still-Face para analisar os comportamentos interativos dos bebês. Diferenças significativas foram observadas nos comportamentos de autorregulação. Todos os bebês apresentaram o efeito still-face e de recuperação e os bebês a termo apresentaram o efeito carry-over. Os resultados contribuem para o planejamento de intervenções que auxiliem as mães a promoverem interações diádicas mais positivas.
\end{abstract}

Palavras-chave: nascimento prematuro, relações mãe-criança, regulação emocional

\section{Face-to-Face Still-Face: Comparación entre Conductas Interactivas de Bebés Nacidos a Término y Prematuros}

\begin{abstract}
Resumen: Estudios han mostrado diferencias en las conductas de autorregulación de bebés, de acuerdo con su edad gestacional. Este estudio buscó comparar las conductas interactivas de bebés nacidos a término y prematuros en el paradigma experimental Face-toFace Still-Face (FFSF). Treinta bebés nacidos prematuros y treinta a término fueron observados en el procedimiento experimental del FFSF que consiste en la exposición del bebé a dos episodios de interacción con la madre y a un episodio en el que se interrumpe la interacción. Se utilizó de una adaptación del Sistema de Codificación y Análisis de las Conductas Infantiles expresadas en Still-face para analizar las conductas interactivas de los bebés. Se observaron diferencias significativas en las conductas de autorregulación. Los bebés mostraron los efectos still-face y de recuperación, y los bebés a término presentaron un efecto carry-over. Los resultados contribuyen para planificar intervenciones que auxilien a las madres a promover interacciones diádicas más positivas.
\end{abstract}

Palabras clave: nacimiento prematuro, relaciones madre-niño, regulación emocional

\footnotetext{
${ }^{1}$ Universidade Estadual Paulista Júlio de Mesquita Filho, Bauru-SP, Brazil

${ }^{2}$ Universidade Federal da Grande Dourados, Dourados-MS, Brazil

${ }^{3}$ Universidade do Porto, Porto, Portugal

${ }^{4}$ Instituto Politécnico de Lisboa, Lisboa, Portugal
}

Article derived from the master's thesis of the first author under the supervision of the second author and co-supervision of the third author, defended in 2016, in the Postgraduate Program in Developmental Psychology and Learning at Universidade Estadual Paulista Júlio de Mesquita Filho. Support: The study was funded by the São Paulo State Research Support Foundation (Fundação de Amparo à Pesquisa do Estado de São Paulo, FAPESP) Process No. 2014/10653-4

Correspondence address: Taís Chiodelli. Rua Caetano Sampieri, 4-25, apto. 54, Bauru-SP, Brazil. CEP 17.012-460. E-mail: tais.chiodelli@hotmail.com
Face-to-Face Still-Face (FFSF) (Tronick, Als, Adamson, Wise \& Brazelton, 1978) is an experimental paradigm that allow researchers to observe infant regulatory behaviors, from their responses to maternal unavailability (Adamson \& Frick, 2003). This paradigm consists of three successive episodes. In the first episode, the mother and infant are seated in face-to-face interaction (first episode - play) and the mother can maintain a normal interaction with their infant. In second episode (the still-face episode), the mother is instructed to look at the infant while keeping a still (neutral) face and to refrain from talking, smiling, or touching the infant. In the third and last episode, mothers return to a normal interaction (third episode - reunion) (Tronick et al., 1978). 
Studies have compared the infants' behaviors over the three episodes of FFSF (Adamson \& Frick, 2003; Mesman, van IJzendoorn, \& Bakermans-Kranenburg, 2009). During the still-face episode, infants tend to exhibit positive interactive behaviors in an attempt to resume interaction with their mother. Not being successful, they can try to exhibit behaviors to manage stress that could indicate their ability to self-regulate their emotions. In addition, infant shows more negative interactive behaviors and less positive engagement behaviors (Adamson \& Frick, 2003; Mesman et al., 2009). According to Tronick et al. (1978), the change of frequency of these behaviors corresponds to the still-face effect that remains for little time, even after resumption of the interaction.

Comparisons of infants' behaviors across the episodes of FFSF may also suggest two other effects, the carry-over and the recovery effect. In carry-over, infants exhibit more negative and less positive responses from the play from the reunion episodes. In the recovery effect, infants recover from the still-face episode to the reunion episode, to a more positive interaction (Mesman et al., 2009).

However, little attention was paid to the reunion episode in studies conducted with FFSF. Coppola, Aureli, Grazia and Ponzetti (2016) analyzed which factors affected the resumption of the mother-infant interaction. The authors observed that the mother's sensitivity during face-to-face and play interaction at the infant's three months of age (history of interaction), and the correspondence of the dyad states during the play episode (FFSF at the infant's six months of age) were predictive variables of the infant responses observed in the reunion episode independently. These results suggest that a history of interaction with an emotionally available mother can contribute to the resumption of a positive interaction in the reunion episode. In opposite sense, dyads with mothers who have low emotional availability in the long run may have difficulty in repairing the failures that occur in interaction.

In a more recent study, Boeve, Beeghly, Stacks, Manning and Thomason (2019), using the actor-partner interdependence model, described the mother's and infant's contributions to the dyadic affective exchanges that occur throughout FFSF. The results indicated that the positive affect shown by the mothers in the play episode was a predictor of the infant positive affect in the reunion episode, which suggests that the mothers were able to help infants regulate their emotions. The infant's negative affect in the play episode predicted greater maternal negative affect in the reunion episode, suggesting that the infant negative affect can influence the mother respond after resuming the interaction. In addition, both the positive affect of the mother and the infant in the play episode were predictors of the dyadic positive affect in the reunion episode. The authors suggested that infants who exhibit positive behaviors in non-stressful situations are more likely to exhibit the same behaviors to recover from a stressful event.

Seixas, Barbosa and Fuertes (2017) described the organization infant self-regulatory behaviors during the FFSF episodes, identifying three patterns: Positive Social Orientation reflects the infants' tendency to elicit social interaction and exhibit positive affect during the FFSF (i.e., infant looks at the mother's face, looks at the mother's body, reaches toward or touches the adult, makes positive vocalizations, or smiles), Negative Social Orientation reflects the infants' tendency to exhibit negative affect and distancing behavior during the FFSF (i.e., makes protest vocalizations, cries, arches or pushes away from the mother, or attempts to escape from the mother by turning away from the mother), and Oriented to Self-comfort reflects the infant's tendency to engage in self-directed coping behaviors during the FFSF (i.e., infant mouths his or her hands, mouths objects, closes his or her eyes, looks away from the mother, self touches, squeezes one hand against the other).The Positive Social Orientation pattern was the most frequent at three and nine months of age, followed by the Negative Social Orientation pattern (which increased at nine months old). The authors identified an overall $78.6 \%$ stability in these self-regulatory patterns from the three to nine months in 98 full-term infants.

The infant ability to regulate their behavior and emotions develop gradually in the interactions that occur with their caregivers, through a mutually regulated dyadic communication system in which, moment by moment, both the infant and the mother modify their affective and behavioral states considering the affective and behavioral states of the other (Beeghly \& Tronick, 2011; Tronick, 1989). These interactions are characterized by the transition from a positive and coordinated affective state to a negative and uncoordinated affective state, with brief interruptions and return of the interaction (Tronick, 1989).

Regarding the emotional self-regulation of infants prematurely born (before 37 weeks of gestation), the literature points to the occurrence of difficulties (Provenzi et al., 2017; Sansavini et al., 2015; Woodward, Lu, Morris, \& Healey, 2016) that seem to occur due to the immaturity of his nervous system at birth and its initial history of exposure to stressful events during the hospitalization period in the Neonatal Intensive Care Unit (NICU). These factors contribute for preterm infants may require more attention and help from their caregivers to calm themselves (Beeghly $\&$ Tronick, 2011), with impacts on their development (Valeri, Holsti, \& Linhares, 2015).

Prematurity is characterized as a risk factor for child development and can be associated with developmental delays, difficulties with self-regulation, language and learning difficulties (Buffone, Eickman, \& Lima, 2016; Fuentefria, Silveira, \& Procianoy, 2017; Granemann \& Anache, 2017). These complications resulting from preterm birth can contribute to a less adaptive mother-infant interaction.

The World Health Organization (WHO, 2018) analyzed the prevalence of preterm births in 184 countries and found that the rate of prematurity worldwide ranges from $5 \%$ to $18 \%$. In Brazil, a population-based study conducted using the Live Birth Information System (Sistema de Informações sobre Nascidos Vivos, SINASC) identified that the prevalence of prematurity in Brazil is 12\% (Henriques et al., 2019). The current rate remains high, indicating prematurity as a public health problem, constituting a condition that requires adequate monitoring of the infant after birth. 
Korja, Latva and Lehtonen (2012) carried out a systematic literature review that included 29 studies, of which 18 were about mother-preterm infant interaction (gestational age less than 37 weeks and weight less than 2,500 grams). The authors observed inconsistences in the results by indicating that, in five studies, there were no differences or the quality of interaction between the mother-preterm infant dyads was better than that of their full-term peers, and 13 studies pointed to differences in the interactive behaviors of the dyads, being that preterm infants continued to differ from those born at term until the two years of corrected age. Variations in maternal behaviors were identified and more frequently in the preterm infant's first six months of corrected age than full-term infants. For Montirosso, Borgatti, Trojan, Zanini and Tronick (2010), from the sixth month onwards, the mothers adapt better and become more responsive to their preterm infants. The interaction time between the dyad is longer, their infants become more skilled and some concerns cease to exist, such as those related to the infant's survival.

In the context of FFSF, Montirosso et al. (2010) compared 50 mothers and infants preterm and at term born, aged between six to nine months old and did not observe significant differences in the socioemotional behaviors of the dyads in the three episodes. The preterm sample consisted of 25 infants with a mean gestational age of 32.1 weeks, of both genders (11 girls and 14 boys). Infants in both groups had a still-face effect and increased the emission of negative behaviors in the reunion episode. After the occurrence of the still-face episode, the frequency of negative behaviors did not return to the initial indexes, which means that the infants presented the carry-over effect. They also observed that infants in both groups looked more at their mothers after the still-face episode, exploring less the environment. On the other hand, they identified differences in the self-regulatory behavior of each group. Preterm infants showed more distancing behavior from their mothers during the three episodes of FFSF and more social monitoring behaviors, such as looking at the caregiver's face and neutral vocalizations, in the reunion episode. With regard to synchrony, the authors observed that it was greater in the reunion episode, for both groups. According to the authors, the results indicated that the reunion episode also has stressful effects for the infant and requires the dyad to readjust to the interaction.

In the study by Hsu and Jen (2008), infants preterm and at term born, with two months of corrected age, were compared in relation to the infant's gaze direction behaviors (looking at the mother's face, looking away, eyes closed for at least one second) and affect (positive, neutral and negative facial expressions) during interaction and after its resumption by the caregivers. They observed that both responded differently to the still-face episodes, showing variations in the behaviors of looking at the mother and positive and negative affect. Preterm infants had a longer duration and lower latency of negative affect throughout the episodes. According to the authors, this result may suggest less maternal support for regulation and difficulties in the behavioral organization of the preterm infant to regulate itself.

Yaari et al. (2018) observed differences in the emotional regulation behaviors of infants born very preterm (gestational age between 24 to 32 weeks), moderate preterm infants (gestational age between 32 to 34 weeks) and full-term infants (between 37 to 41 weeks) at four months of age, with corrected age for preterm infants. In comparisons between groups, infants born prematurely (from both groups) emitted significantly less positive affect and more looking away at the play and reunion episodes than full-term infants. Preterm infants had a carry-over effect for positive affect behaviors and the three groups had the same effect for negative affect behaviors. Differences in self-comfort behaviors were also identified. Very preterm infants significantly exhibit less of these behaviors throughout the episodes. Moderate preterm presented the effects of still-face and recovery, and those born at term did not show significant differences in these behaviors during FFSF. The authors pointed out that the differences between the groups of preterm may indicate more developed emotional regulation skills in moderate preterm infants. As for the difference in infants born at term, the result could indicate that these infants present better emotions regulation skills.

Chiodelli, Rodrigues, Pereira, Lopes dos Santos and Fuertes (2020), when investigating the interaction of 15 mothers and very preterm infants, with three to four months of corrected age, in the context of FFSF, observed that the infants had the still-face effect and significantly increased the Positive Social Orientation behaviors (looking at the mother's body and positive motor agitation). In the comparisons between the play and reunion episodes, there were no differences in the Negative Social Orientation behaviors. These results suggest that the infants were able to resume interaction at the same levels observed in the play episode and to self-regulate their behaviors and emotional in the face of a stressful situation.

It is observed that there are discrepancies in studies regarding the effects of prematurity on the behaviors of infants during interaction with the mother, pointing out the importance of further investigations in this area, since their results can support specific interventions with mothers of infants, premature or not. Korja et al. (2012) indicated inconsistencies related to a very broad definition of prematurity, suggesting that future studies should have a detailed description of the gestational age, considering the different competences of the preterm infant. In the case of comparative studies, the use of the corrected age is a parameter that allows for dialog with the literature. This study aimed to compare interactive behaviors of infants born at term and preterm according to the experimental Face-toFace Still-Face paradigm (FFSF).

\section{Method}

This is a descriptive, observational, and cross-sectional study. 


\section{Participants}

The study included 60 infants divided according to gestational age, 30 preterm infants (PT) and 30 full-term infants (FT), recruited at: (1) a public university extension project that monitored the development of infants during the first year of life, (2) an early intervention service at a Specialized Rehabilitation Center, or (3) a public maternity clinic that monitored the development of infants born prematurely and weighing less than 1500 grams. The three institutions were located in a city of the state of São Paulo.

PT infants were between three to four months of corrected age $(M=3.4$ months old $)$ and FT infants were, between three and four months old $(M=3.4)$. The mean gestational age of the infants in the PT was 32.5 weeks and the mean birth weight was $1,873.3$ grams. The infants FT had a mean gestational age of 38.7 weeks and a mean weight of 3,373.8 grams. Cesarean section was the most frequent mode of delivery for both groups, and $70 \%$ of the PT remained hospitalized in the NICU for more than 21 days. However, the reason for this hospitalization was to gain necessary weight.

With regard to the mothers, the mean age of the PT sample was 29.4 years old, and 28.5 years old in the FT sample, the majority of the mothers of the two groups engaged in paid work. The mean years of schooling for the mothers in the PT sample was 12.1, and 13.7 years for those in the FT sample. Most infants from both samples lived in households with their parents and siblings. There was a significant in both samples difference for gestational age $(t=-12.474$; $p=<0.001)$, birth weight $(t=-13.819 ; p=<0.001)$, infant's hospital stay $(t=5.413 ; p=<0.001)$ and maternal education $(t=-2.226 ; p=0.030)$ ( $t$ test of independent samples, chisquare test, and Fisher's exact test).

\section{Instruments}

Coding System and Analysis of Infant Behaviors Expressed in Still-Face adapted by Chiodelli et al. (2020). The infant's interactive behaviors were analyzed based on the adaptation of the Coding System and Analysis of Infant Behaviors Expressed in Still-Face, which organizes the infant's interactive behaviors in three categories: (1) Positive Social Orientation (looking at the mother's face, looking at the mother's body, smiling, reaching for the mother, exhibit positive or neutral vocalizations, showing positive excitation, such as swinging the arms and legs accompanied by looking towards the mother and/or smiles), (2) Negative Social Orientation (exhibiting vocal protest, escaping from the mother, arching the body, pushing away from the mother, crying, exhibiting negative facial expression and excessive motor activity, such as moving the arms and legs accompanied by negative facial expressions), and (3) Oriented to Self-comfort (mother's gaze aversion, closing the eyes, oral mouth, oral objects, avoiding mother, squeezing hands against each other and handling objects).

\section{Procedure}

Data collection. For data collection, two cameras, two tripods, a chair and a feeding chair for infants with reclining back and adjustable height were used, adapted for the study with the removal of the feeding tray. This adaptation was also carried out in other studies with preterm infants (Chiodelli et al., 2020). The Sony Vegas Pro 13.0 software was used to pair the videos.

The infants were identified by the medical records of three institutions. At the appropriate age of the infant, the mother was invited to participate in the research and signed the Free and Informed Consent Form. Then, a time was scheduled for observation, and guidelines were provided on the procedure. Data was collected in each institution at an individual laboratorial room, duly prepared.

The mother's interaction with the infant was observed in the context of Face-to-Face Still-Face (FFSF) (Tronick et al., 1978), lasting up to nine minutes, divided into three episodes (up to three minutes each). In the first and the third episodes (play and reunion, respectively), the mother was instructed to interact with her infant as she usually do to, although without using toys or other objects. In the second episode (still-face), the mother is instructed to maintain eye contact with their infant, but without responding to his behaviors, and presenting a neutral facial expression. The change between episodes was signaled by the experimenter. The presence of the infant's discomfort, identified by crying lasting up to 15 seconds, was a criterion adopted to interrupt or change the shooting condition (suspension of the still-face episode and return of the interaction). During the nine minutes, the infant sat in an adapted feeding chair and the mother sat in a chair in front of it.

Data analysis. A micro-analytic analysis of fivesecond to five-second intervals was used to compute infant behaviors during the three episodes of FFSF, totaling 36 fivesecond intervals per episode (Chiodelli et al., 2020). In cases where there was a difference in the number of intervals, due to interruption for the infant crying, the frequencies were weighted in view of the number of intervals analyzed.

Twelve videos $(30 \%)$ of the sample were submitted to inter-rater agreement coding, carried out by the first author and an independent trained coder. The values of the intraclass correlation coefficient were greater than 0.8 , being characterized as excellent agreement (Cicchetti, 1994).

The Statistical Package for the Social Sciences (SPSS) software, version 21, was used for data analysis. The Student's t-test was used to compare study samples across the FFSF episodes, and ANOVA with post hoc Tukey was used to test intra-group comparisons.

\section{Ethical Considerations}

The present study complied with the rules foreseen in Resolution No. 466/2012 of the National Commission 
for Ethics in Research, being approved by the Ethics Committee of the School of Sciences of Universidade Estadual Paulista Júlio de Mesquita Filho - UNESP (Process No.: 11187/46/01/12), by the scientific committee of SORRIBauru, and by the Foundation for Medical and Hospital Development (Fundação para o Desenvolvimento Médico e Hospitalar, FAMESP).

\section{Results}

The behaviors of the PT and FT infants were compared across three episodes of FFSF. The analyses were performed considering each category of infant behavior. Table 1 shows the statistically significant results in each episode.

In the play episode, considering the Positive Social Orientation category, there are differences in the direction of the gaze. PT infants had higher means of looking at the mother's face than FT. In opposite sense, FT infants looked more at the mother's body that PT. In Negative Social Orientation, infants differed in their excessive motor activity, with higher means for infants in the PT sample. In the Selfcomfort category, it was observed that the behaviors of handling objects and total Self-comfort were significantly more frequent for FT infants than in PT.

In the still-face episode, similar to that observed in the play episode, the FT infants looked significantly more at their mothers' bodies (Positive Social Orientation) and handling more objects (Self-comfort) than PT. Another difference refers to the behavior of squeezing hands against each other (Self-comfort), more frequent for PT than in other infants.

Keeping the pattern observed in the previous episodes, the FT, in the reunion episode, differed from PT in the behaviors of looking at the mother's body (Positive Social Orientation) and handling objects (Self-comfort). In addition, they differed in total Self-comfort behaviors with higher means for FT than in PT while closing the eyes being more frequent for infants' PT than in FT.

Table 1

Comparisons between the interactive behaviors of PT and FT infants during the three episodes of FFSF

\begin{tabular}{|c|c|c|c|c|c|c|}
\hline & \multicolumn{2}{|c|}{ PT Sample } & \multicolumn{2}{|c|}{ FT Sample } & \multirow[b]{2}{*}{$t$} & \multirow[b]{2}{*}{$p$} \\
\hline & Mean & $S D$ & Mean & $S D$ & & \\
\hline \multicolumn{7}{|l|}{ Play episode } \\
\hline \multicolumn{7}{|l|}{ PSO } \\
\hline Looking at the mother's face & 24.73 & 8.36 & 18.26 & 11.72 & -2.462 & 0.017 \\
\hline Looking at the mother's body & 7.71 & 6.56 & 12.23 & 9.07 & 2.207 & 0.031 \\
\hline \multicolumn{7}{|l|}{ NSO } \\
\hline Excessive motor activity & 2.70 & 3.71 & 0.93 & 1.50 & -2.419 & 0.019 \\
\hline \multicolumn{7}{|l|}{$\mathrm{SC}$} \\
\hline Handling objects & 4.89 & 8.82 & 13.77 & 10.69 & 3.508 & 0.001 \\
\hline Total SC & 23.40 & 15.94 & 36.70 & 16.83 & 3.143 & 0.003 \\
\hline \multicolumn{7}{|l|}{ Still-Face episode } \\
\hline \multicolumn{7}{|l|}{ PSO } \\
\hline Looking at the mother's body & 0.49 & 0.81 & 3.92 & 8.57 & 2.184 & 0.033 \\
\hline \multicolumn{7}{|l|}{$\mathrm{SC}$} \\
\hline Squeezing hands against each other & 4.74 & 7.75 & 1.49 & 2.71 & -2.167 & 0.034 \\
\hline Handling objects & 12.74 & 12.31 & 20.34 & 12.28 & 2.395 & 0.020 \\
\hline \multicolumn{7}{|l|}{ Reunion episode } \\
\hline \multicolumn{7}{|l|}{ PSO } \\
\hline Looking at the mother's body & 6.36 & 6.78 & 11.61 & 11.32 & 2.174 & 0.034 \\
\hline \multicolumn{7}{|l|}{$\mathrm{SC}$} \\
\hline Closing the eyes & 1.23 & 2.35 & 0.30 & 0.91 & -2.020 & 0.048 \\
\hline Handling objects & 2.66 & 6.16 & 10.95 & 10.84 & 3.640 & 0.001 \\
\hline Total SC & 21.20 & 12.49 & 31.55 & 22.31 & 2.217 & 0.031 \\
\hline
\end{tabular}

Note. $\mathrm{PSO}=$ Positive Social Orientation; $\mathrm{NSO}=$ Negative Social Orientation; SC $=$ Self-Comfort; PT Sample = Preterm infants; FT Sample = Fullterm infants; FFSF $=$ Face-to-Face Still-Face; ${ }^{*} p$ value obtained by the Student's t test. 
For intra-group comparisons, all the behaviors that compose the categories of Positive Social Orientation, Negative Social Orientation, and Self-comfort were also considered. Table 2 shows the results of the infants in the PT sample. As for the Positive Social Orientation behaviors, the infants in this sample (PT) significantly decreased the means of the behaviors of looking at the mother's body, smiling, and reaching for the mother, as well as the total of this category, between the play and still-face episodes. Only the behavior of looking at the mother's body increased significantly between the still-face and reunion episodes. In Negative Social Orientation, the infants cried significantly more during the episodes, the comparisons were significant between the still-face and reunion episodes, and between the reunion and play episodes. Excessive motor activity was more frequent in the still-face episode compared to the play episode and decreased significantly after resumption of the interaction with the mother.

In the Self-comfort behaviors, an increase was observed between the play and still-face episodes in the emission of looking away from the mother's face, squeezing hands against each other, handling objects and total Self-comfort. These same behaviors decreased significantly after resumption of the interaction with the mother, in the reunion episode. In the comparisons between the play and reunion episodes, the mean of closing the eyes increased significantly.

Table 2

Comparisons of the PT infants' behaviors across the FFSF episodes

\begin{tabular}{|c|c|c|c|c|c|c|}
\hline & $\begin{array}{c}\text { Play episode } \\
M(S D) \\
\end{array}$ & $\begin{array}{c}\text { Still-Face episode } \\
M(S D)\end{array}$ & $\begin{array}{c}\text { Reunion episode } \\
M(S D)\end{array}$ & $F$ & $p$ & Post hoc Tukey \\
\hline \multicolumn{7}{|l|}{$\mathrm{PSO}$} \\
\hline Looking at the mother's face & $25(8.36)$ & $21(10.23)$ & $22(11.29)$ & 1.205 & 0.305 & \\
\hline Looking at the mother's body & $8(6.53)$ & $0(0.80)$ & $6(6.79)$ & 14.744 & $<0.001$ & $\mathrm{P}>\mathrm{SF} ; \mathrm{SF}<\mathrm{R}$ \\
\hline Smiling & $7(6.61)$ & $2(4.93)$ & $4(5.55)$ & 5.319 & 0.007 & $\mathrm{P}>\mathrm{SF}$ \\
\hline Reaching for the mother & $2(3.12)$ & $0(0.59)$ & $2(3.02)$ & 3.455 & 0.036 & $\mathrm{P}>\mathrm{SF}$ \\
\hline Positive or neutral vocalizations & $8(7.56)$ & $4(5.95)$ & $5(6.24)$ & 2.860 & 0.063 & \\
\hline Positive excitation & $3(5.53)$ & $4(6.89)$ & $5(5.96)$ & 0.278 & 0.758 & \\
\hline Total PSO & $47(20.27)$ & $32(22.64)$ & $43(21.99)$ & 4.184 & 0.018 & $\mathrm{P}>\mathrm{SF}$ \\
\hline \multicolumn{7}{|l|}{ NSO } \\
\hline Negative facial expression & $6(8.41)$ & $8(7.65)$ & $10(10.44)$ & 1.704 & 0.188 & \\
\hline Vocal protests & $6(7.74)$ & $9(10.38)$ & $6(4.63)$ & 1.841 & 0.165 & \\
\hline Escaping from the mother & $0(0.44)$ & $1(1.02)$ & $1(2.09)$ & 0.915 & 0.405 & \\
\hline Arching the body & $1(1.44)$ & $2(4.86)$ & $1(2.91)$ & 0.687 & 0.506 & \\
\hline Pushing away from the mother & $2(5.45)$ & $0(0.54)$ & $1(1.80)$ & 2.302 & 0.106 & \\
\hline Crying & $1(2.27)$ & $2(3.74)$ & $6(8.75)$ & 6.512 & 0.002 & $\mathrm{P}<\mathrm{R} ; \mathrm{SF}<\mathrm{R}$ \\
\hline Excessive motor activity & $3(3.72)$ & $7(7.84)$ & $3(4.93)$ & 4.682 & 0.012 & $\mathrm{P}<\mathrm{SF} ; \mathrm{SF}>\mathrm{R}$ \\
\hline Total NSO & $23(23.89)$ & $31(25.93)$ & $33(29.08)$ & 1.338 & 0.268 & \\
\hline \multicolumn{7}{|l|}{$\mathrm{SC}$} \\
\hline Mother's gaze aversion & $14(8.01)$ & $20(10.06)$ & $13(8.31)$ & 5.767 & 0.004 & $\mathrm{P}<\mathrm{SF} ; \mathrm{SF}>\mathrm{R}$ \\
\hline Closing the eyes & $0(0.54)$ & $0(0.74)$ & $1(2.35)$ & 3.672 & 0.029 & $\mathrm{P}<\mathrm{R}$ \\
\hline Oral mouth & $2(3.98)$ & $5(8.57)$ & $3(4.41)$ & 2.347 & 0.102 & \\
\hline Oral objects & $0(1.65)$ & $0(1.63)$ & $1(1.56)$ & 0.015 & 0.986 & \\
\hline Avoiding mother & $2(3.46)$ & $2(2.69)$ & $1(1.28)$ & 0.614 & 0.543 & \\
\hline Squeezing hands against each other & $0(0.96)$ & $5(7.75)$ & $1(2.88)$ & 6.757 & 0.002 & $\mathrm{P}<\mathrm{SF} ; \mathrm{SF}>\mathrm{R}$ \\
\hline Handling objects & $5(8.82)$ & $13(12.31)$ & $3(6.15)$ & 9.422 & $<0.001$ & $\mathrm{P}<\mathrm{SF} ; \mathrm{SF}>\mathrm{R}$ \\
\hline Total SC & $23(15.91)$ & $45(20.80)$ & $21(12.46)$ & 18.504 & $<0.001$ & $\mathrm{P}<\mathrm{SF} ; \mathrm{SF}>\mathrm{R}$ \\
\hline
\end{tabular}

Note. PSO = Positive Social Orientation; NSO = Negative Social Orientation; SC = Self-Comfort; PT Sample = Preterm infants; FFSF = Faceto-Face Still-Face; $\mathrm{P}=$ Play episode; $\mathrm{SF}=$ Still-Face episode; $\mathrm{R}=$ Reunion episode; ${ }^{*} p$ value obtained by ANOVA. 
The same comparisons were made with infants in the FT sample (Table 3). Regarding the Positive Social Orientation category, the FT infants significantly reduced the looks at the mother's body, smiling and total Positive Social behaviors in the comparisons between the play and still-face episodes. In the reunion episode the total of Positive Social behaviors and the looks at mothers increased significantly in the stillface episode, presenting similar values to the ones presented in the play episode. Sift in Negative Social Orientation was compared from the play and still-face episodes as well as between from play and to the reunion episode. The negative facial expressions, vocal protest and total Negative Social
Orientation increased significantly from the play episode to the still-face episode, and from the play episode to the reunion episode. Crying increased significantly from the play to the reunion episodes and there was a significant increase in the excessive motor activity behavior between the play and still-face episodes. Regarding Self-comfort, the behaviors of mother's gaze aversion and total Self-comfort increased significantly between the play and still-face episodes and decreased significantly between the still-face and reunion episodes. The frequency of handling objects after resuming interaction with the mother (comparison between the stillface and reunion episodes) significantly decreased.

Table 3

Comparisons between the behaviors of the infants in the FT sample across the FFSF episodes

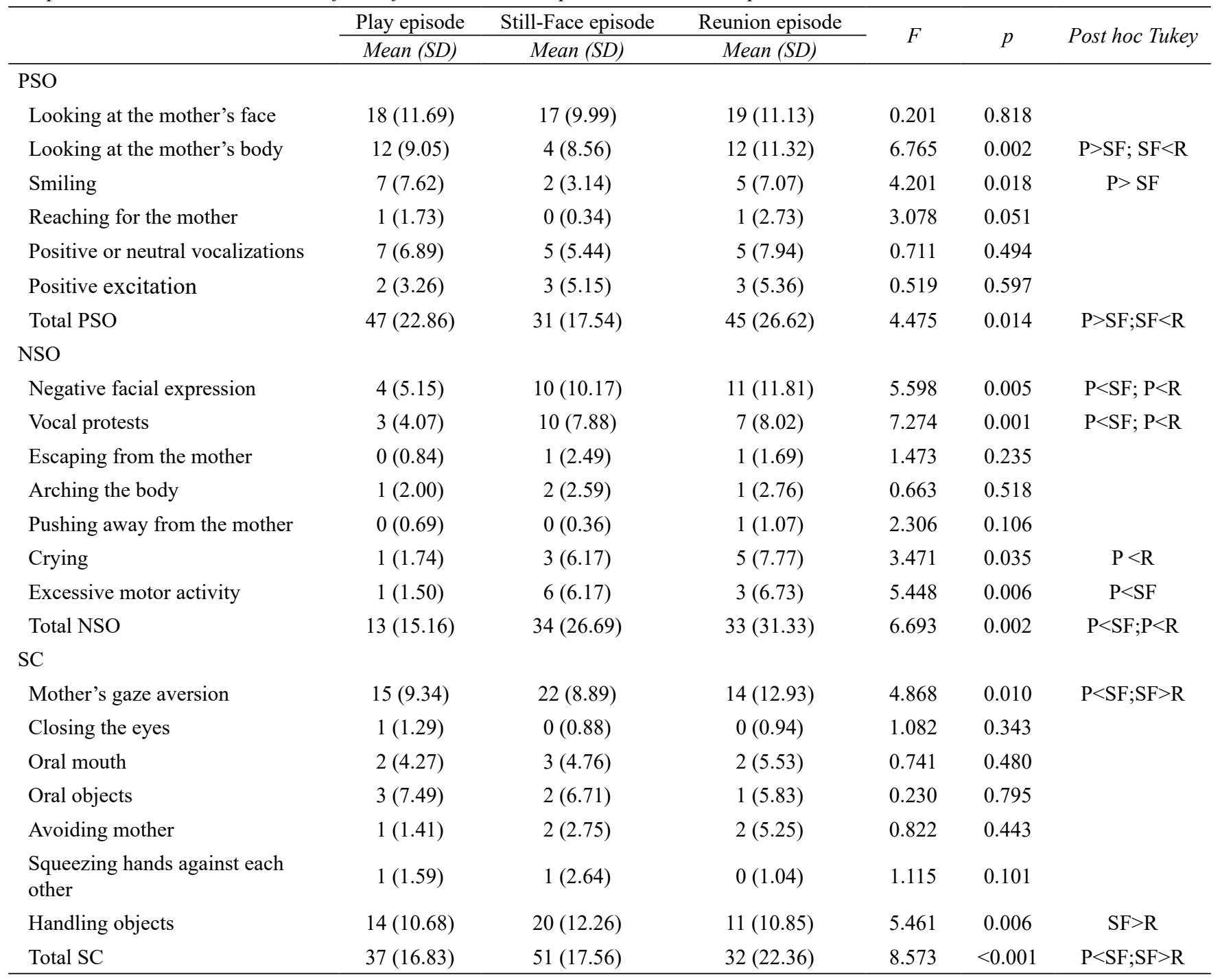

Note. PSO = Positive Social Orientation; NSO = Negative Social Orientation; SC = Self-Comfort; FT Sample = Full-term infants; FFSF = Face-to-Face Still-Face; $M=$ Mean; $S D=$ Standard Deviation; $\mathrm{P}=$ Play episode; $\mathrm{SF}=\mathrm{Still}-F a c e$ episode; $\mathrm{R}=\mathrm{Reunion}$ episode; * $p$ value obtained by ANOVA. 


\section{Discussion}

The behaviors of infants born prematurely and at term were compared in the three episodes of FFSF. In the play episode, positive interaction behaviors were expected in response to maternal interactive behaviors, which was observed in infants of two samples, although they differed in toward the direction of the gaze. PT infants had more eye contact with the mother. One of the effects of prematurity may be the difficultness of mothers to read newborns initial needs. Thereby, mothers can try harder to involve infants in interaction, via eye contact, reinforcing this behavior as it occurs (Agostini, Neri, Dellabartola, Biasini, \& Monti, 2014). Although in low frequency, it was observed that preterm had more excessive motor activity than full-term infants. This behavior can indicate the infant's discomfort in remain sitting on the chair.

In the still-face episode, the infants were expected to selfregulate their emotions in the absence of maternal interactive behaviors, which happened to infants in both groups, presenting the still-face effect (Adamson \& Frick, 2003). This result corroborates the body of knowledge found in the context of FFSF by Hsu and Jeng (2008), Jean and Stack (2012), Montirosso et al. (2010) and Yaari et al. (2018). Full-term infants handling objects more than PT, while PT infants squeezed their hands more, a pattern similar to the self-comfort behaviors shown by the moderate preterm infants in the study by Yaari et al.(2018), differing from infants born very prematurely and the term, who did not show significant differences in self-comfort behaviors during the FFSF episodes.

In the reunion episode, the infants were expected to gradually resume interaction with the mother, decreasing Selfcomfort behaviors and increasing Positive Social Orientation behaviors. However, the FT infants responded less to the interaction with their mothers, showing significantly more Self-comfort behaviors than the infants in the PT sample, such as handling objects, similar to that found by Jean and Stack (2012) in their study. In the present study, this result was observed in the play and reunion episodes, which could suggest that the FT infants were not receiving the necessary support from their mothers to repair the failures of the interaction, using their own resources as a way to control and transform affective states on their own (Beeghly \& Tronick, 2011; Tronick, 1989) and, consequently, they spent less time on social engagement than their preterm peers. One possible explanation remains in the age of the FT infants, chronologically younger than PT infants.

In the intra-group comparisons conducted, differences and similarities were observed between the infants of the both samples considering the three episodes. PT and FT infants showed significant differences in the frequency of total positive interactive behaviors, which decreased from the play episode to the still-face episode (still-face effect). In the reunion episode, the behaviors recovered to the basal values observed during play episode (recovery effect), although the increase was statistically significant only for the FT sample. For the PT infants, the differences between the play and stillface episodes were also significant for specific behaviors as looking at the mother's body, smiling, and reaching for the mother. For FT infants, the effect was observed for the behaviors of looking to the mother's body and smiling. For both samples, recovery occurred significantly only for the behavior of looking at the mother's body.

As for the Negative Social Orientation behaviors, it was observed that their total number behaviors in this category did not differ statistically across the FFSF episodes in the PT sample. There was an increase in the mean of negative behaviors presented from the play episode to the still-face episode, which can be a reaction to the maternal still-face. Yet, there was a slight increase in the total mean of negative behaviors from the still-face episode to the reunion episode. Crying was the behavior that most increased over these episodes. This fact is similar to the carry-over effect, with the presence of negative interactive behaviors in the reunion episode, even though positive social interaction behaviors occur. Such results can be related to the short- and long-term effects observed in the development of infants born preterm and exposed to neonatal stress and pain, due to invasive and painful procedures for the infant, during the hospitalization period, as presented by Valeri et al. (2015).

This initial experience can contribute to infants being more sensitive to changes in the environment and showing more irritation and negative affect. In addition, they can also indicate the possible intentionality of crying that is present around five months of age, according to a study conducted with parents of infants in the first semester of life (Nunes, Aquino, \& Salomão, 2018). As for the infants in the FT sample, it was observed that the frequency of Negative Social Orientation behaviors was low in the play episode, significantly increased from the play episode to the still-face episode, and remained in the reunion episode at the same level as in the still-face episode, increasing significantly in relation to the play episode. For this sample, it is observed that the carry-over effect was clearer. The maintenance of these behaviors can also suggest a difficulty for term infants to reorganize themselves in view of the resumption of interaction with the mother and the permanence of the stillface effect for a longer time. According to Tronick (1989), the infant's self-regulatory and negative affect behaviors are not interrupted immediately after the mother resumes interaction with them, maintaining these behaviors in the next few minutes, pointing out that the infants are responding under control of what happened previously in the interaction.

Regarding the Self-comfort behaviors of the infants in the PT Group, it was observed that they did not have difficulties in self-regulation during the still-face episode and were able to resume interaction with their mothers, presenting a result similar to that obtained by Yaari et al. (2018) in the group of moderate preterm infants and by Chiodelli et al. (2020) with very preterm infants. This result may also suggest that the mothers were able to support their infants in their selfregulatory processes. For FT infants, the total Self-comfort behaviors increased from the play episode to the still-face episode, and decreased significantly from the still-face episode to the reunion episode. The behaviors of mother's 
gaze aversion and handling objects were the most frequent in this category, although they decreased restored maternal availability in the reunion episode.

The present study compared behaviors of infants born prematurely and at term in relation to the exhibition of interactive behaviors with their mothers. The results indicated that PT infants contribute to the interactions with their mothers, increasing their responses and engagement to their mothers. In addition, infants identified maternal unavailability and also self-regulated, resuming the interaction after the occurrence of the still-face episode, contributing to the stress regulation processes. The little difference observed between the two groups, suggests a similar pattern of interaction that can be due to the corrected age of the PT infants. Age correction resulted in PT infants up to three months older, which may mean more interaction time with the mother, compared to FT infants. Corrected age can give be misleading, informing falsely that PT infants are better self-regulating and resume interaction with the mother faster than FT. Although age correction is recommended in research, the interaction time of these PT infants with their mothers is earlier than that of infants born at term, resulting in fewer differences between groups. It is possible that comparative studies on the mother-infant interaction with preterm infants and full-term infants, using chronological age as a criterion may give clues to the influence of prematurity on the mother-infant interaction. Therefore, considering both corrected and chronological could be helpful to identify differences in faster and more efficient way.

Some limitations were observed, such as the statistically significant difference in maternal education; mothers of term infants had more years of study than those of preterm infants. No analyses were conducted to consider the impact of this variable. However, in studies such as Barbosa et al. (2019) and Seixas et al. (2017), maternal education did not present a significant association with maternal and infant interactive behaviors. Another limitation refers to the lack of analysis of maternal behaviors during the interaction with the infant in the context of FFSF, which could contribute to the discussion in a more comprehensive manner. Considering the interaction as a dynamic and bidirectional process (mutually regulated), it is suggested that other research studies carry out analyses that consider maternal-infant interactive sequences and the functions that the behaviors of the dyad members will present in the interaction.

Our results suggest that interventions can be helpful, with PT or FT infants, as early age as three months old, in order to help dyads to co-regulate and support infants' efforts to reengage in positive states. Nevertheless, it is possible that dyads with preterm infants can profit even more from these interventions.

\section{Referências}

Adamson, L. B., \& Frick, J. E. (2003). The still face: A history of a shared experimental paradigm. Infancy, 4(4), 451-473. doi:10.1207/S15327078IN0404_01
Agostini, F., Neri, E., Dellabartola, S., Biasini, A., \& Monti, F. (2014). Early interactive behaviours in preterm infants and their mothers: Influences of maternal depressive symptomatology and neonatal birth weight. Infant Behavior \& Development, 37(1), 86-93. doi:10.1016/ j.infbeh.2013.12.003

Barbosa, M., Beeghly, M., Gonçalves, J. L., Moreira, J., Tronick, E., \& Fuertes, M. (2019). Predicting patterns of regulatory behavior in the Still-Face Paradigm at 3 months. Infancy, 24(4), 501-525. doi:10.1111/infa.12293

Beeghly, M., \& Tronick, E. (2011). Early resilience in the context of parent-infant relationships: A social developmental perspective. Current Problems in Pediatric and Adolescent Health Care, 41(7), 197-201. doi:10.1016/j.cppeds.2011.02.005

Boeve, J. L., Beeghly, M., Stacks, A. M., Manning, J. H., \& Thomason, M. E. (2019). Using the Actor-Partner Interdependence Model to assess maternal and infant contributions to mother-infant affective exchanges during the Still-Face Paradigm. Infant Behavior \& Development, 57, 101351. doi:10.1016/j.infbeh.2019.101351

Buffone, F. R. R. C., Eickman, S. H., \& Lima, M. C. (2016). Processamento sensorial e desenvolvimento cognitivo de lactentes nascidos pré-termo e a termo [Sensory processing and cognitive development of preterm and full term infants]. Cadernos Brasileiros de Terapia Ocupacional, 24(4), 695-703. doi:10.4322/0104-4931.ctoAO0731

Cicchetti, D. V. (1994). Guidelines, criteria, and rules of thumb for evaluating normed and standardized assessment instruments in psychology. Psychological Assessment, 6(4), 284-290. doi:10.1037/1040-3590.6.4.284

Chiodelli, T., Rodrigues, O. M. P. R., Pereira, V. A., Lopes dos Santos, P., \& Fuertes, M. (2020). Interactive behaviors between mothers and their prematurely born infants in the face-to-face still-face paradigm. Estudos de Psicologia (Campinas), 37, e180164. doi:10.1590/ 1982-0275202037e 180164

Coppola, G., Aureli, T., Grazia, A., \& Ponzetti, S. (2016). Reunion patterns in the still-face paradigm as predicted by maternal sensitivity and dyadic coordination. Infancy, 21(4), 453-477. doi:10.1111/infa.12115

Fuentefria, R. N., Silveira, R. C., \& Procianoy, R. S. (2017). Motor development of preterm infants assessed by the Alberta Infant Motor Scale: Systematic review article. Jornal de Pediatria, 93(4), 328-342. doi:10.1016/ j.jped.2017.03.003

Granemann, J. L., \& Anache, A. A. (2017). Processos de aprendizagem e desenvolvimento de crianças prematuras: Uma temática essencial e salutar às áreas de educação e saúde [Learning processes and premature child development: An essential themes and salutary to education and health areas]. Interfaces da Educação, 8(22), 388-415. doi:10.26514/inter.v8i22.1646 
Henriques, L. B., Alves, E. B., Vieira, F. M. S. B., Cardoso, B. B., D’Angeles, A. C. R., Cruz, O. G., ... Saraceni, V. (2019). Acurácia da determinação da idade gestacional no Sistema de Informações sobre Nascidos Vivos (SINASC): Um estudo de base populacional [Accuracy of gestational age assessment in Brazilian Information System on Live Birth (SINASC): A population study]. Cadernos de Saúde Pública, 35(3), e00098918. doi:10.1590/0102-311x00098918

Hsu, H. C., \& Jeng, S. F. (2008). Two-month-olds' attention and affective response to maternal still face: A comparison between term and preterm infants in Taiwan. Infant Behavior \& Development, 31(2), 194-206. doi:10.1016/ j.infbeh.2007.10.008

Jean, A. D. L., \& Stack, D. M. (2012). Full-term and very-low-birth-weight preterm infants' self-regulation behaviors during a still-face interaction: Influences of maternal touch. Infant Behavior \& Development, 35(4), 779-791. doi:10.1016/j.infbeh.2012.07.023

Korja, R., Latva, R., \& Lehtonen, L. (2012). The effects of preterm birth on mother-infant interaction and attachment during the infant's first two years. Acta Obstetricia et Gynecologica Scandinavica, 91(2), 164-173. doi:10.1111/j.1600-0412.2011.01304.x

Mesman, J., van IJzendoorn, M. H., \& BakermansKranenburg, M. J. (2009). The many faces of the still-face paradigm: A review and meta-analysis. Developmental Review, 29(2), 120-162. doi:10.1016/j.dr.2009.02.001

Montirosso, R., Borgatti, R., Trojan, S., Zanini, R., \& Tronick, E. (2010). A comparison of dyadic interactions and coping with still-face in healthy pre-term and full-term infants. British Journal of Developmental Psychology, 28(Pt. 2), 347-368. doi:10.1348/026151009X416429

Nunes, L. L., Aquino, F. S. B., \& Salomão, N. M. R. (2018). Concepções parentais sobre intencionalidade comunicativa em bebês aos 3 e 6 meses [Parental conceptions of communicative intentionality in infants at 3 and 6 months]. Psico-USF, 23(1), 71-82. doi:10.1590/1413-82712018230107

Organización Mundial de la Salud. (2018). Nacimientos prematuros [Preterm birth]. Retrieved from http://www. who.int/es/news-room/fact-sheets/detail/preterm-birth
Provenzi, L., Fumagalli, M., Bernasconi, F., Sirgiovanni, I., Morandi, F., Borgatti, R., \& Montirosso, R. (2017). Very preterm and full-term infants' response to socioemotional stress: The role of postnatal maternal bonding. Infancy, 22(5), 695-712. doi:10.1111/infa.12175

Sansavini, A., Zavagli, V., Guarini, A., Savini, S., Alessandroni, R., \& Faldella, G. (2015). Dyadic coregulation, affective intensity and infants' development at 12 months: A comparison among extremely preterm and full-term dyads. Infant Behavior \& Development, 40, 29-40. doi:10.1016/j.infbeh.2015.03.005

Seixas, I., Barbosa, M., \& Fuertes, M. (2017). Contributos para a auto-regulação do bebé no Paradigma Face-toFace Still-Face [Patterns of infant self-regulation in Face-to-Face Still-Face paradigm]. Análise Psicológica, 35(4), 469-485. doi:10.14417/ap.1280

Tronick, E., Als, H., Adamson, L., Wise, S., \& Brazelton, T. B. (1978). The infant's response to entrapment between contradictory messages in face-to-face interaction. Journal of the American Academy of Child Psychiatry, 17(1), 1-13. doi:10.1016/S0002-7138(09)62273-1

Tronick, E. Z. (1989). Emotions and emotional communication in infants. American Psychologist, 44(2), 112-119. doi:10.1037/0003-066X.44.2.112

Valeri, B. O., Holsti, L., \& Linhares, M. B. M. (2015). Neonatal pain and developmental outcomes in children born preterm: A systematic review. The Clinical Journal of Pain, 31(4), 355-362. doi:10.1097/ AJP.0000000000000114

Yaari, M., Rotzak, N. L., Mankuta, D., Harel-Gadassi, A., Friedlader, E., Eventoy-Friedman, S., ... Yirmiya, N. (2018). Preterm-infant emotion regulation during the still-face interaction. Infant Behavior \& Development, 52, 56-65. doi:10.1016/j.infbeh.2018.05.008

Woodward, L. J., Lu, Z., Morris, A. R., \& Healey, D. M. (2016). Preschool self regulation predicts later mental health and educational achievement in very preterm and typically developing children. The Clinical Neuropsychologist, 31(2), 404-422. doi:10.1080/138540 46.2016.1251614 
Taís Chiodelli is a Ph.D. candidate of the Postgraduate Program in Developmental Psychology and Learning at Universidade Estadual Paulista Júlio de Mesquita Filho, Bauru-SP, Brazil.

Olga Maria Piazentin Rolim Rodrigues is a Professor of the School of Science at Universidade Estadual Paulista Júlio de Mesquita Filho, Bauru-SP, Brazil.

Veronica Aparecida Pereira is a Professor of the School of Human Sciences at Universidade Federal da Grande Dourados, Dourados-MS, Brazil.

Pedro Lopes dos Santos is a Professor of the School of Psychology and Education Sciences at Universidade do Porto, Porto, Portugal.

Marina Fuertes is a Professor of the Lisbon School of Education at Instituto Politécnico de Lisboa, Lisboa, Portugal.

\section{Authors' Contribution:}

All the authors made substantial contributions to the conception and design of this study, to data analysis and interpretation, and to the manuscript revision and approval of the final version. All the authors assume public responsibility for the content of the manuscript.

Editor:

Edna Maria Marturano
Received: Sep. 06, 2019

1st Revision: May 18, 2020

2nd Revision: Jul. 15, 2020

Approved: Jul. 21, 2020
How to cite this article:

Chiodelli, T., Rodrigues, O. M. P. R., Pereira, V. A., Lopes dos Santos, P., \& Fuertes, M. (2021). Face-to-face still-face: Comparison between interactive behaviors of full-term and preterm infants. Paidéia (Ribeirão Preto), 31, e3102.doi:https://doi.org/10.1590/1982-4327e3102 